\title{
ESTUDO DA VIABILIDADE CELULAR DA LEVEDURACERVEJEIRA FRENTE AOS TEORES ALCOÓLICOS PRODUZIDOS
}

\author{
$\underline{\text { Roquelí Gabriela do Nascimento de Oliveira }}{ }^{1}$; Milenna Santos Silva ${ }^{2}$; Giovani \\ Brandão Mafra de Carvalho ${ }^{3}$. \\ 1. Bolsista FAPESB/UEFS, Graduanda em Engenharia de Alimentos, Universidade Estadual de Feira de Santana, \\ e-mail: gabinoli12@ hotmail.com \\ 2. Participante do projeto de pesquisa Núcleo de Inovação em Tecnologias de Fermentação, Departamento de \\ Tecnologia, Universidade Estadual de Feira de Santana, e-mail: milasantos.eng@gmail.com \\ 3. Orientador, Departamento de Tecnologia, Universidade Estadual de Feira de Santana, e-mail: \\ gbmafra@yahoo.com.br
}

PALAVRAS-CHAVE: Viabilidade; leveduras; fermentação.

\section{INTRODUÇÃO}

As leveduras Saccharomyces cerevisiae tem sido amplamente utilizada em fermentações alcoólicas por se tratarem de microrganismos que apresentam as principais características desejáveis para uso industrial: rápida transformação de açúcares em álcool, atividade celular em ambiente ácido e alta tolerância às condições severas (Nobre, 2005). A tolerância da levedura ao seu produto de fermentação, o etanol, é bastante significante em relação à eficiência da conversão de seus açucares (Cabrini; Gallo, 1999. apud Camolez; Mutton, 2005).

A utilização dessas leveduras na produção de cervejas de alta densidade requer a suplementação nutricional da mesma, com ácidos graxos insaturados como ácido oleico (DRAGONE et al., 2007), já que esse tipo de fermentação diminui a viabilidade celular e torna a fermentação mais lenta devido à alta pressão osmótica e ao aumento dos níveis de etanol (Almeida e Silva, 2005). O Óleo de Coco é um produto natural funcional que contem altos níveis de ácido oleico, além de apresentar efeitos nutracêuticos (BONTEMPO, 2008). Sendo assim, uma ótima opção para suplementar a levedura em questão.

Neste sentido o presente trabalho teve como objetivo avaliar a influência do óleo de coco como suplemento, na viabilidade celular da levedura, durante a fermentação do mosto de alta densidade, além de comparar a viabilidade celular da levedura suplementada com estudos in vitro através do acompanhamento pela contagem em câmara de Neubauer, avaliar os níveis alcoólicos produzidos e realizar o acompanhamento analítico da fermentação;

\section{MATERIAL E MÉTODOS}

As fermentações foram realizadas no Laboratório de Fermentação (LAF) do departamento de Tecnologia da Universidade Estadual de Feira de Santana. Os materiais utilizados foram: o óleo de coco extra virgem COPRA, mostos de $17^{\circ}$ Platô, $19,5^{\circ}$ platô e $22^{\circ}$ platô previamente preparados e mantidos sob refrigeração e a levedura do tipo Saccharomyces cerevisiae de baixa fermentação (Lager). Os parâmetros analisados foram: Brix, densidade, concentração de etanol, viabilidade celular e capacidade fermentativa das leveduras em cada amostra.

\section{RESULTADOS E/OU DISCUSSÃO}

As concentrações de açúcar de cada amostra do mosto e a quantidade de óleo de coco adicionada como suplemento foram dadas nas seguintes proporções:

Tabela1: Numero das amostras com suas respectivas quantidades de óleo de coco adicionado e ${ }^{\circ}$ Brix de mosto usado. 


\begin{tabular}{|c|c|c|}
\hline Amostras & $\begin{array}{c}\text { Quantidade de óleo } \\
\text { adicionado }(\mu \mathrm{l})\end{array}$ & $\begin{array}{c}\text { Concentração do mosto } \\
\left({ }^{\circ} \text { Brix }\right)\end{array}$ \\
\hline 1 & 0,5 & 17 \\
\hline 2 & 0,5 & 22 \\
\hline 3 & 220 & 17 \\
\hline 4 & 220 & 19,5 \\
\hline 9 & 265 & 19,5 \\
\hline 10 & 0,04521 & 17 \\
\hline Branco $17^{\circ} \mathrm{P}$ & 0 & 19,5 \\
\hline Branco $19,5^{\circ} \mathrm{P}$ & 0 & 22 \\
\hline Branco $22^{\circ} \mathrm{P}$ & 0 & \\
\hline
\end{tabular}

$\mathrm{Na}$ figura a seguir, é possível visualizar a viabilidade celular das amostras.

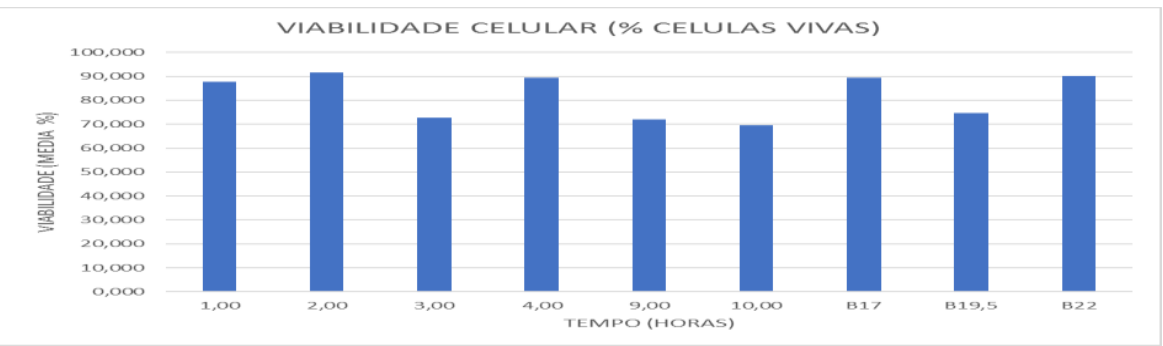

Figura1: Viabilidade celular de cada amostra em função do tempo de fermentação, expressa em porcentagem.

Nas amostras feitas com mosto de $17^{\circ}$ Platô, apenas a amostra 1 apresentou um aumento na viabilidade, o que pode ser explicado pela quantidade de óleo de coco $(0,5 \mu 1)$. Já que na amostra 4 a quantidade de óleo de coco é muito maior $(220 \mu \mathrm{l})$, isso prova que uma quantidade muito elevada não causa um efeito tão satisfatório no aumento da viabilidade celular, ou seja, o aumento da viabilidade depende da quantidade de óleo de coco utilizado. Nas amostras feitas com mosto de $19,5^{\circ}$ Platô, os resultados foram menores que o branco, o que indica que em um mosto de $19,5^{\circ}$ platô a presença de óleo de coco, independentemente da quantidade, não foi capaz de aumentar a viabilidade celular. Nas amostras feitas com mosto de $22^{\circ}$ Platô, a quantidade de óleo de coco determinou a variação da viabilidade. Na amostra 2 houve um crescimento na viabilidade, enquanto na amostra 3 houve uma diminuição significativa na viabilidade, comparados ao branco nas mesmas condições. Ou seja, a quantidade de óleo de coco usada para suplementação não deve ser tão alta, pois o excesso pode afetar na viabilidade de forma negativa.

No gráfico a seguir, é expressa a variação da viabilidade das amostras durante a fermentação.

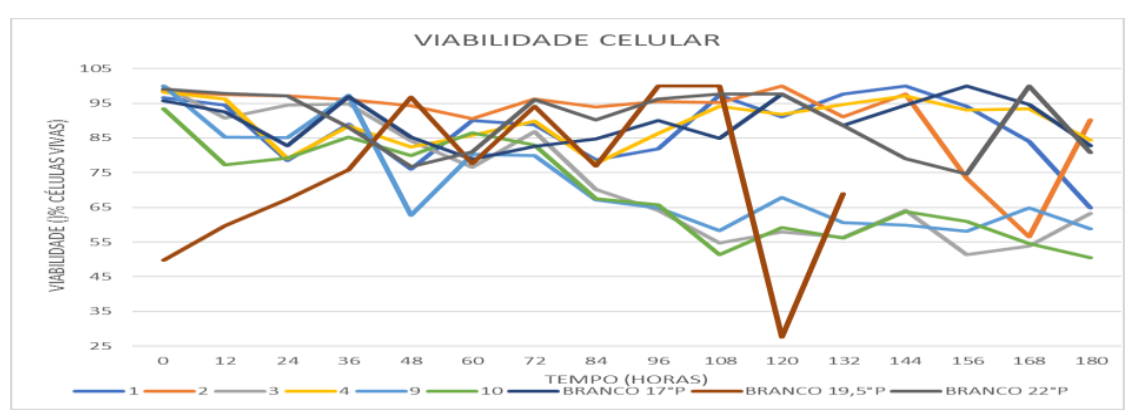

Figura2: Viabilidade celular de cada amostra em função do tempo de fermentação. 
Na figura 2 é possível perceber que as amostras 9, 10 e 3 apresentaram menor desempenho no crescimento celular e as amostras 1, 4, Branco $22^{\circ}$ platô e Branco $17^{\circ}$ platô apresentaram os melhores resultados no crescimento celular, durante as 180 horas de fermentação. Para as amostras do mosto de $17^{\circ}$ platô, esse desempenho pode estar relacionado à menor concentração de açúcar inicial e, consequente, proporcional quantidade de açúcar total ao final da fermentação. A amostra Branco 19,5 Platô, não apresentou mais células viáveis antes das 132 horas de. Devido a isso, podemos concluir que nas amostras 9 e 10, a presença de células viáveis até as últimas horas de fermentação, mesmo que numa quantidade pequena, se deve à presença de óleo de coco na amostra.

A variação da concentração de açúcar em cada amostra é expressa no gráfico a seguir:

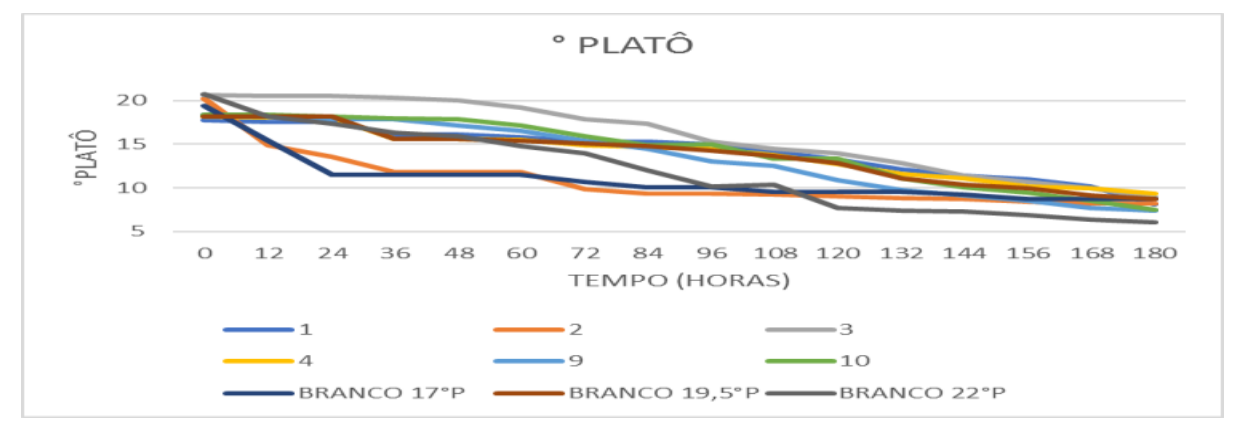

Figura3: Variação de ${ }^{\circ}$ Platô nas amostras fermentadas.

Em todas as amostras, o valor de ${ }^{\circ}$ platô inicial é maior que o valor final. Isso se deve a transformação dos açucares presentes no mosto em etanol durante a fermentação. Os valores de ${ }^{\circ}$ Platô de cada amostra é o referente ao indicado na descrição de cada amostra. Ao final da fermentação a diminuição do ${ }^{\circ}$ platô das amostras foi proporcional ao valor inicial.

A concentração de etanol nas amostras é apresentada no gráfico a seguir:

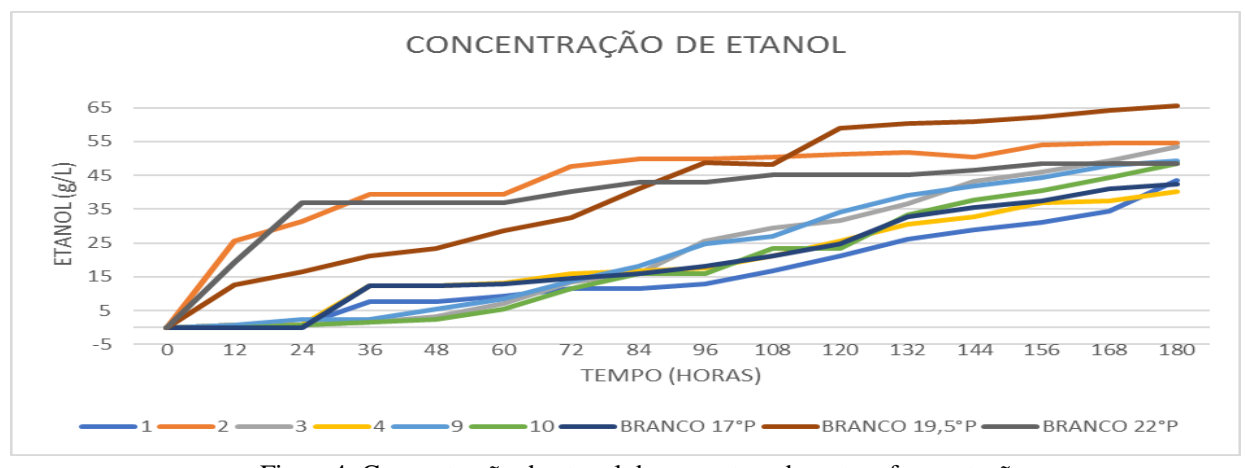

Figura4: Concentração de etanol das amostras durante a fermentação.

Em todas as amostras, a concentração inicial de etanol é igual a zero, por que no início da fermentação os açucares ainda não foram convertidos a etanol. As amostras 1, 3, 4, 9, 10 e Branco $17^{\circ}$ Platô, apresentaram uma quantidade de etanol pouco maior que zero na primeira análise, feita depois de 12 horas do inicio da fermentação. Enquanto as amostras 2, Branco $19,5^{\circ}$ Platô e Branco $22^{\circ}$ Platô na mesma contagem já apresentaram uma quantidade de etanol maiores que $10 \mathrm{~g} / \mathrm{L}$. As amostras 10 e Branco $17^{\circ}$ Platô demoraram mais tempo para constar uma quantidade considerável de etanol. Na amostra 2, o que pode explicar sua alta concentração de etanol já nas primeiras horas de fermentação, é a presença de óleo de coco numa proporção favorável à conversão dos açucares.

A variação da densidade do mosto em cada amostra é mostrada no gráfico a seguir: 


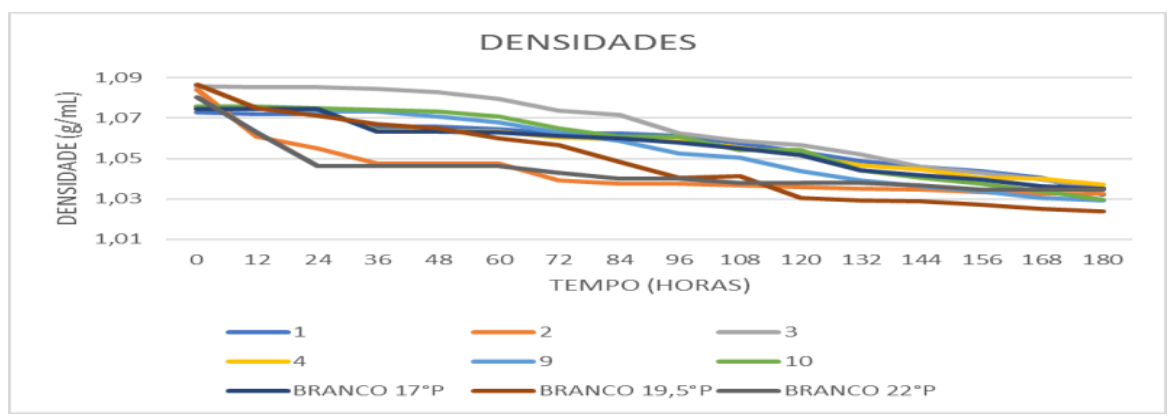

Grafico5: Densidade do mosto de cada amostra durante o processo fermentativo.

Como o mosto usado foi de alta densidade, as densidades iniciais das amostras são mais elevadas e diminuem gradativamente. A maior densidade ao início da fermentação é da amostra Branco $19,5^{\circ}$ platô, com $1,0864 \mathrm{~g} / \mathrm{L}$, que ao final da fermentação foi a menor densidade, com 1,024g/L. Como esperado, essa amostra apresentou a maior concentração de etanol ao final da fermentação. As amostras 2 e 3 apresentaram as maiores formações de etanol ao final da fermentação devido a concentração dos mostos utilizados, porem a amostra 3 , possivelmente, por conter uma quantidade maior de óleo de coco, apresentou uma certa resistência na diminuição da densidade ao longo do tempo da fermentação, ou seja, apresentou uma dificuldade maior para começar a fermentar, enquanto a amostra 2, com menor quantidade de óleo de coco, acompanhou o decrescimento da densidade do Branco correspondente. Ao final da fermentação todas as amostras apresentaram valores de densidades próximos, exceto a amostra Branco $19,5^{\circ}$ platô, que apresentou uma densidade inferior. Os maiores níveis de decrescimento de densidade foram das amostras 2 , branco $19,5^{\circ}$ platô e branco $22^{\circ}$ platô, o que está relacionado com o maior consumo de açucares durante a fermentação.

\section{CONSIDERAÇÕES FINAIS}

Diante dos resultados manifestos, podemos concluir que a amostra 2 foi a mais beneficiada pelo aumento da viabilidade proporcionada pela suplementação do óleo de coco, bem como a maior formação de etanol a partir dos açucares presentes no mosto, mesmo contendo uma das menores concentrações de açúcar durante toda fermentação. Assim podemos concluir que o presente projeto se mostrou como uma forma eficaz de suplementar a levedura cervejeira com uso do óleo de coco em mostos de $17^{\circ}$ Platô, aumentando a viabilidade celular e a capacidade fermentativa da levedura suplementada, trazendo resultados satisfatórios do crescimento das leveduras durante a fermentação.

\section{REFERÊNCIAS}

ALMEIDA e SILVA, J, B. Cerveja. In: VENTURINI FILHO, W. G. Tecnologia de bebidas. São Paulo: Edgard Blucher, 2005.

BONTEMPO, M., O Poder Medicinal do Coco e do Óleo de Coco Extra Virgem. São Paulo: Editora Alaude, 2008.

CAMOLEZ, M. A.; MUTTON, J. R. Influência de microrganismos contaminantes sobre o processo fermentativo. Revista STAB, São Paulo, v. 23, n. 5, maio/jun. 2005.

CARVALHO, G. B. M. Obtenção de cerveja usando banana como adjunto e aromatizante. 2009. 163f. Tese (Doutorado em Biotecnologia Industrial) - Escola de Engenharia de Lorena, Universidade de São Paulo, 2009.

DRAGONE, G; SILVA, D.P.; ALMEIDA E SILVA, J.B.; LIMA, U.A. Improvement of the etanol productivity in a high gravity brewing at pilot plant scale. Biotechnology Letters, v.25, p. 1171-1174, 2003.

NOBRE, T, P. Viabilidade celular de Saccharomyces cerevisiae cultivada em associação com bactérias contaminantes da fermentação alcoólica. Piracicaba, 2005. 